\title{
Making sense of diodes and sodium: vision, visuality and the everyday experience of infrastructural change
}

\begin{abstract}
The recognition of vision as a powerful register for organising urban space locates lighting technologies at the heart of urban experience. Recently, scholars have established that lighting technologies shape not just what we see but how we see, drawing attention towards light as that 'with which we see'. This article shifts attention from the role of lighting in shaping what and how people see, to how people make sense of changes to their visual sensorium - from what lighting infrastructures do to what is done with them. By following older residents living in the London Borough of Newham along routine travels on foot at night, I demonstrate how they make sense of the Council's initiative to upgrade their 19,500 street-lamps with Light Emitting Diodes. I demonstrate how such infrastructural change exposes an uneven geographical distribution of and access to light and darkness with potentially detrimental consequences for the formation of public life after dark. Recognising how light infrastructures are reframed through everyday life, I demonstrate how LEDs do not necessarily produce their desired effects and how light clutter and light bleed might contribute to producing nocturnal atmospheres where people feel safe and confident.

Broadening the understanding of how different technologies and light sources are important for the formation of inclusive nocturnal publics the article sets out a 'politics of visibility' that recognises the role of lighting in creating visibility for and of residents.
\end{abstract}

Key words: light, vision, night, public space, infrastructure, atmosphere 


\section{Introduction}

It is true that we now have acetylene and electrical lighting instead of oil lamps; but the enthusiasm for the progress achieved in lighting makes us sometimes forget that the essential thing is not the lighting itself but what becomes more visible. (Simmel quoted in Thrift, 1994, p. 220)

While the earliest attempts at providing public lighting in $16^{\text {th }}$-century Europe were sporadic and more concerned with making certain buildings of importance visible (Schivelbusch, 1995), systematic attempts endured throughout the $18^{\text {th }}$ and $19^{\text {th }}$ centuries, providing visibility for a host of professional and leisurely activities (Koslofsky, 2011; Melbin, 1987). The continual development of more efficient, brighter and, crucially, cheaper lighting technologies enabled state officials, local authorities and police forces to fasten their visual grip on the city, mobilising public order and ensuring the safety of emerging forms of 'night work' and (bourgeois) forms of 'night life' (Beaumont, 2015; Ekirch, 2005; McQuire, 2005; Schlör, 1998). Along with street lighting, the introduction of the lens, the telescope, the camera, the cinema, and the television provided new types of vision that altered how people saw and how they represented themselves, producing new forms of urban visual culture (Schlör, 1998; Thrift, 1996).

However, the awe and fascination with which new lighting technologies were received quickly diminished (Ekirch, 2005; Koslofsky, 2011; Schivelbusch, 1995) and as brighter, clearer and more consistent lighting spread across and between cities, the emerging ubiquitous lighting grid was woven into the fabric of the city as the "backbone of everyday life" (Nye, 2013, p. 19). In his critique of modern urban life around the turn of the $20^{\text {th }}$ century, Georg Simmel, quoted at the head of the section, claimed that the introduction of new technologies succeeded in derailing attention from what was more critically at stake, namely, the visual culture that these technologies produced and reproduced for the seemingly unaware urbanite. With the slow mainstreaming of new technologies of visibility and their associated ways of seeing, vision emerged as a disciplinary regime in the design and planning of urban space (Foucault, 1977), working through the imposition of legibility, promoting a "rational order in remarkably visual aesthetic terms" (Scott, 1998, p. 4). It is from such observations that Nigel Thrift (1994, p. 200) questions how lighting technologies altered ways of seeing, feeling and doing things in the city, ultimately transforming the "nature of subjectivity".

While the transition from combustion to filament lighting emerged in tandem with a growing preoccupation with the visual and aesthetic impacts of places, it seems pertinent to question how the contemporary global transition from electric to electronic lighting, courtesy of the introduction of DMX controlled LED lighting systems, impacts on vision and everyday life in $21^{\text {st }}$-century cities. This article considers how the introduction of LED lighting in London is changing its visual landscape and culture by drawing on ethnographic fieldwork carried out between 2013 and 2015 in the London Borough of Newham. In 2013 the council initiated a wholesale upgrade of its entire street lighting infrastructure, which saw the predominant sodium powered street lights (SON) refurbished or replaced in piecemeal fashion, street by street, with metal halide (MH) or LED. As older residents in Newham are shown to feel less confident and secure walking the streets alone at night (Greater London Authority, 2015; London Borough of Newham, 2013, 2016b), I wanted to explore how the technological 
change impacts or not on the way older residents see, feel and do things at night. I conducted 14 walk-along interviews with 20 older residents, between 48 and 72 years, reenacting routine walks such as walking home from the station or the bus stop, dog walking, visiting relatives or going to the local shop ${ }^{1}$.

The article critically assesses the rationale that undergirds contemporary lighting design and light planning practice, by foregrounding how people respond to and make use of urban lighting to support everyday practices, revealing how the urban lit environment is assembled through a host of practices. In doing so, I take great inspiration in recent scholarship in geography and anthropology that has explored how people inhabit infrastructures (Latham \& Wood, 2015; Silver, 2015; Simone, 2014) and more specifically how urban lighting infrastructures are incorporated into everyday life (Bille, 2014, 2019; Pain, MacFarlane, Turner, \& Gill, 2006; Pink \& Leder Mackley, 2014; Pink \& Sumartojo, 2017), recognising that ways of seeing and feeling are contingent on the messy and unplanned trajectories of everyday life in the city (see Edensor, 2017a; Kumar, 2015; Shaw, 2018). The article contributes to these debates in two ways; first, I show that by shifting focus from what lighting infrastructures are claimed to do, to what people do with them enables geographers to account for the contingent and complex effects of urban environments and technological change; secondly, I demonstrate how geographical knowledge about the lived experience of urban infrastructures can challenge the highly visual and aesthetic focus in urban planning practice. I contend that the claimed effects of a luminous upgrade, such as switching to LEDs, are at best presumptuous, and neglect how the experience of the urban night-time draws on a range of light sources that emerge through a plethora of unplanned and unsolicited lighting practices-ones that often prove more important to how people see, feel and do things in the city.

I unfold this argument in three sections: first, I introduce the case study and the underlying rationale that drives the technological transition from sodium to LED. With the aim of developing an understanding of these changes, situated in the everyday urban encounters with light, I subsequently draw on discussions in the humanities and social sciences to develop a conceptual framework for understanding how people respond to and negotiate infrastructural change. Through a number of successive vignettes, I unfold how people make sense of and co-produce the urban, lit environment in everyday life and draw out the conceptual implications for geographical thought, suggesting the need to develop a progressive 'politics of visibility' that recognises the role of lighting in creating visibility for and of resident.

\footnotetext{
${ }^{1}$ I conducted walk-along interviewees with seven males and 13 females, seven of which I accompanied alone and 12 of which were formed in couples. The walks were predominantly around Canning Town, Custom House, Beckton, and Plaistow. The majority of the residents had lived in their house of flat for over 20 years witnessing waves of urban change throughout their neighbourhood. Two residents and two couples were part of families that over generations had lived in the area, recalling the times when the street lighting was gas fuelled, while two couples had recently moved just after the turn of the century. The residents lived in a mix of Victorian terraces, council estate flats, and maisonettes under different types of tenure.
} 


\section{LED and the technological fix}

Satellite photos of nocturnal London capture the distribution of different light technologies across the city: the golden carpet that is seen in figure 1 reaching towards London's peripheral, primarily residential areas reveal a prevalence of SON lights - the preferred light source since its introduction in the 1960s. The 'white' lights, which stretch across central and West London reveal the prominence of newer lighting technologies such as LEDs, MH, halogen and fluorescent lights (and heritage lighting such as the gaslights in Covent Garden). In addition to indicating a functional division of the city's centre and periphery (Meier \& Henckel, 2017), scholars have suggested that the geographic distribution of lighting technologies indicates socio-economic differences (Edensor \& Millington, 2009, 2010; Sutton \& Elvidge, 2015) and reveal narratives of technological progress or stagnation (Edensor, 2017a; Schulte-Römer, 2013).

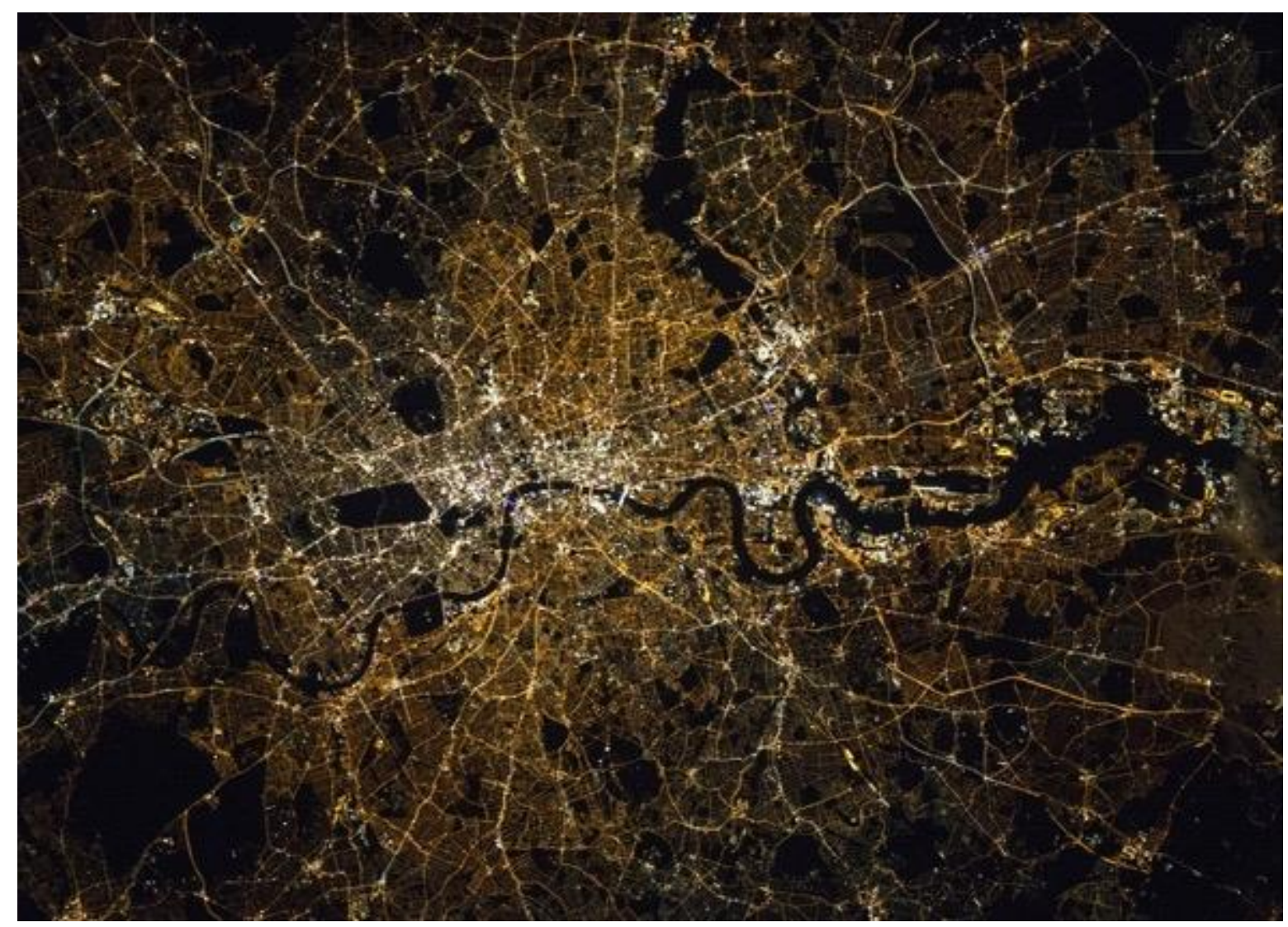

Figure 1. London at night, captured by NASA astronaut Kjell Lingren, 29 September 2015 (source: NASA, 2015).

Since 2015, a number of London's 32 boroughs have joined the global trend of 'upgrading' their urban lighting infrastructures by introducing new lighting technologies - often in the bluer and brighter end of the spectrum. In Newham the Council claim that "LED street lights can reduce carbon emissions, save money in the long run and make people feel safer" (London Borough of Newham, 2018, para. 1) because the lighting is "brighter" and assumed to "make Newham look better and feel safer" (London Borough of Newham, 2016a). The celebration of LEDs as a technological fix in urban planning and design has become common practice, reducing public spending in times of austerity (they consume $60-70 \%$ less energy and last up to five times that of competing technologies), combatting crime and improving 
the sense of safety at night, while mitigating against climate change (Gandy, 2017; SchulteRömer, 2015; Shaw, 2018). The technological capacities of LEDs offer a promise for the future city that justifies and legitimates its widescale introduction 'onto' the city.

To support such initiatives quantitative measures for the performance of different light sources are often foregrounded. LEDs mainly produce light at the correlated colour temperature (CCT) 3-6000K which in comparison to SON lights (2100-2700K) is a bluer hue of 'white' closer to that of daylight (6500K). When installed at the same light levels, measured in lux, a street scene illuminated by LEDs will appear brighter and clearer than spaces lit by alternative sources (F Falchi et al., 2016; Gandy, 2017). While advances in LED technology have made LEDs at $2700 \mathrm{~K}$ common practice for most interior design, local authorities tend to install LEDs at 4-5000K in public spaces and in streets, as the LED is cheaper to produce LEDs with higher CCTs and because the light produces more lumens - the bluer light appears brighter. Its brightness can also be explained by its property to render the colour of an object true to the colour it has in a reference light, such as sunlight. Measured on the Colour Rendition Index from 0 to 100Ra, the colour rendition of LED ( $\approx 70 \mathrm{Ra}$ and up) is roughly three times that of SON ( $\approx 20 R a)$ (Secured by Design, 2016). Effectively, this means that a leafy tree will appear green in LED lighting, compared to shades of yellow under monochrome SON light. In addition, light bulbs such as SON or $\mathrm{MH}$ emit light at $360^{\circ}$ around the source, requiring a reflector on one side to redirect light towards the target. Despite this reflection the fitting will still give off a circular glow - the light bleeds - which is what is known to contribute to light pollution and phenomena such as skyglow - light that unintentionally bleeds upwards, towards the sky. On the contrary, LEDs produce a unidirectional light, radiating from a flat surface towards a target without creating glow and capable of carving out light space in surrounding darkness.

Despite these benefits a growing body of research has documented the wider effects of the bluer, brighter light, detailing the adverse effects on human, animal and plant life (Fabio Falchi, Cinzano, Elvidge, Keith, \& Haim, 2011; Gandy, 2017; Meier, Hasenöhrl, Krause, \& Pottharst, 2015). The detrimental effects of 'blue light' on the circadian rhythm and sleep patterns have, however, been refuted and shown to depend not on the assumed visual impact of light (the CCT, as seen on figure 1), but rather on the non-visual impacts of light in the blue spectrum (430-505nm). The non-visual content of light (malnopic content) that disrupts the circadian rhythm is shown to vary greatly between light sources at any given CCT, meaning that, in effect, an incandescent light bulb at a bedside table could prove more detrimental to sleep patterns than a 4000K or 6000K LED (IES, 2017).

Therefore, it is important to recognise the visual and non-visual impacts of light when seeking to understand how it can shape vision, visuality and the chemical compounds of the body. Just as lighting technologies in modernising cities changed the "nature of subjectivity" (Thrift, 1994, p. 200), the advent of new lighting technologies in the $21^{\text {st }}$ century can engineer vision in ways that influence people's capacity to feel and act in certain ways (see also Amin \& Thrift, 2017). This suggests a need to shift attention away from the technology itself and instead addresses how technologies configure and are configured into wider socio-technical networks that structure spaces and the lives within them. With an interest in exploring how people respond to changes in urban lighting, I therefore turn to debates in the social sciences 
and humanities that explore how people come to make sense of and inhabit urban

infrastructures of light.

\section{(Infra)structures of light}

Historically, artificial urban lighting and illumination has been introduced to organise spaces by distributing visibility and invisibility unevenly across urban and architectural space. In his genealogy of urbanism Michel Foucault argued that the spatial organisation of cities instilled physical and moral order, modelled around the design of the prison, the asylum, the school and working-class housing estates. In Discipline and Punish, he argues that visual technologies such as the telescope, the lens and the light beam allowed authorities to organise spaces through direct observation and surveillance, which crucially came to induce a "state of conscious and permanent visibility" (1977, p. 201). Lighting technologies formed part of an apparatus for distributing bodies into predictable schemata. According to Gilles Deleuze, every such apparatus has "a way of structuring light" (1992, p. 160) and thus of exerting visual control that can never be reduced to the specific lamp, light source or light beam. Rather, the way of structuring light distributes vision and visibility across a network of human and non-human agents, which incidentally shifts attention away from the light source to its effects. The power of visuality therefore works through "a certain concerted distribution of bodies, surfaces, lights, gazes; in an arrangement whose internal mechanisms produce the relation in which individuals are caught up." (Foucault, 1977, p. 202) While lighting technologies are the means for distributing visibility across networked infrastructures and for exerting control over human and non-human agents they are at the same time the result of this socio-technical engagement. As John Pløger reminds us Foucault's notion of apparatus (or dispositif) should never be understood as deterministic, producing inert subjects without agency, but rather as generative of a field of potentiality, as an "interplay between circumstances...[as] a modality possible of effecting....as active" (Pløger, 2008, p. 54). In this sense, lighting infrastructures are both means for exercising control over people in space and results of that very same exercise. Recognising the relational co-production of the built environment, geographers have explored how architectural and urban spaces are coproduced by people, through different modalities of 'resistance' (Middleton, 2010; Spinney, 2010) or routinized everyday practices. For example, Monica Degen and Gillian Rose (2012) argue that the sensory experience and everyday use of buildings cannot be read as causal effects of design and planning intentions, but rather emerge in "the re-assembling of things and subjects in the practising of everyday sociability" (Rose, Degen, \& Basdas, 2010, p. 347). Routinised practices such as shopping or socialising in urban spaces exemplify such 'reassembling', emphasising how people reframe the environment to "fit the parameters of everyday life" (Senie quoted in Degen, DeSilvey, \& Rose, 2008, p. 1919).

Across geography and urban studies a growing interest in infrastructures and architecture support such assertions, suggestion that the "physical and socio-technical fabric of cities" are "seamlessly coproduced, and co-evolve, together within contemporary society" (Graham \& Marvin, 2001, p. 179 emphasis added). With an emphasis on the ways that people come to embody or inhabit infrastructures, the notion of 'lived infrastructures' has gained traction recently as a framework for addressing processes of infrastructural inhabitation and manipulation (Koch \& Latham, 2012; Latham \& Wood, 2015; Mattern, 2014; Simone, 2014; Watson, 2015). With attention directed away from the physical infrastructure or the material building (alone) towards its effects, recent research on street-lighting infrastructures have 
exposed how the introduction of new lighting technologies seem to evade localized everyday experiences (Shaw, 2014) and are insensitive to site specific context (Krause, 2015; SchulteRömer, 2015). Drawing on a detailed study in Northumberland, UK, Rachel Pain, Robert MacFarlane, Keith Turner and Sally Gill (2006) demonstrate how residents' dissatisfaction with poorly performing street-lighting seldom correlates with areas where the coverage of lighting is poor, suggesting that the 'technical fix' of simply replacing old lighting technologies with new ones will have potential little effect (see also Valentine, 1989).

Drawn towards these fine-grained, localized everyday experiences of lighting infrastructures, other research has explored how people make sense of the lit environment 'on the go'. In Sarah Pink and Shanti Sumartojo's (2017) ethnographic study of people's experience of "automated lighting" (2017, p. 4) in Melbourne, Austrailia, they broaden their focus to include contingent light sources and their changing nature over time, and suggest that people respond to and incorporate the unforeseen contingency of changing light and darkness into their configuration of the everyday (2017, pp. 12-13). Rather than causing distress or irritation, residents are shown to actively respond to shifting forces beyond their control and therefore ascribe meaning to them beyond simply enduring their adverse effects. Light infrastructures are therefore not consumed passively, but actualised in practice-a point that Matt Cook and Tim Edensor (2014) stress as they show how moving through an ever changing landscape of light and dark requires of the body to continuously negotiate changes, suggesting that bodily rhythms clash and intersect with otherworldly intensities and qualities that pertain to the human and non-human environment. By emphasising the importance of understanding light and dark as constantly evolving and changing according to the movement through them, Edensor argues that "the play of light provokes onlookers into making sense of landscape" (2017b, p. 619).

This section has drawn attention towards the co-constitutive role of everyday practices aimed in order to develop a line of inquiry that questions how modalities of seeing are shaped through complex engagements with and actualisations of infrastructures and technologies. By stressing that lighting infrastructures distribute the visible and invisible in ways that are absolutely entangled with everyday life practices, I have developed a conceptual framework that allows for more sensitive attention to be directed towards the ways people reframe technologies that are introduced to alter their sensorium to fit into the parameters of their everyday lives in ways meaningful to them.

\section{Making sense of diodes and sodium}

The walk-along interviews took methodological inspiration from Degen and Rose's (2012) study of routine shopping trips in designed urban environments. I asked residents to re-enact a routine walk and describe the lighting in order to "get closer to the unspoken, embodied relational engagements that produce experiences of the urban." (Degen, Rose, \& Basdas, 2010, p. 66) When I met up with the residents they often mentioned that in anticipation of the walk-along interview they had begun to notice the lighting in their street more carefully and how it impacted on how they felt-something they previously had remained happily oblivious towards. This discovery informed the theme of the walk-along interviews and most residents pointed out places that were particularly well-lit compared to bad or dimly-lit places - these typologies often coincided with places that recently had been refurbished opposed to those that hadn't. Inspired by Jeannie Middleton's (2011) study of how 
pedestrians in East London negotiate interruptions to their habituated, purposeful walks, I therefore directed attention towards how the residents made sense of these differently lit spaces they moved through.

\section{Seeing through light}

Many residents played down the importance of lighting to their routine walks and stressed the somewhat pragmatic point that as long as they were able to see where they were going, the type, amount or quality of the light was insignificant. Charlie, a 78-year-old veteran of the Armed Forces, who was born and grew up in Custom House, lives on his own in a ground floor apartment on a council estate and took me along his routine walk to the library. This part of Newham was erased to a mere bombsite in the Blitz during the Second World War, with few buildings predating this period today - the library building among the few. The built environment is a heterogeneous mix of walk-up maisonettes, council estates and tower blocks connected by a web of roads, pathways, and parking lots, all lit in a variety of light systems and sources (mainly SON).

As we walked through the differently lit streets, Charlie remarked that on a general note the "lighting is very poor". In several places he showed how trees had overgrown street lamps, blocking out light, or lamps that had gone out or been smashed and left unrepaired, often for months. While the light might be dim, turned off or overgrown by trees it had never given him any problems seeing. The difference between 'good' and 'bad' lighting, he explained, was not a case of 'light' or 'dark', but rather in "the actual density of the light," with which he meant the amount of light relative to the space next to it. The comparison of the 'density' of the light in different streets was therefore not concerned with darkness or 'bad' lighting in a particular street, but rather with the visibility compared to adjacent spaces: "as long as I can see where I am going I am not really worried about what lighting it is...As long as I can see what is going on around me, it doesn't matter if it is half-light." Seeing, for Charlie, does not necessarily depend on a specific technology or its performance-it can even be half-light.

This became clearer as we approached a street that recently had been refurbished with LEDs. Charlie had: "noticed that in Maplin Road, the lighting is very, very good," appearing remarkably brighter than the yellow light encroaching from the SON lit Freemasons' Road. Yet, as we turned down a SON-lit alleyway, he remarked that he didn't see any worse in these streets. Regardless of the streets lit in "very poor lighting" or "very good" LED lighting, he does not experience problems seeing and does not feel troubled or uncomfortable. As other scholars have noted, people's ability to see and feel comfortable walking in dimly lit areas at night also depends on their familiarity with the space and their ability to orientate themselves in darkness (Kumar, 2015) and negotiating other people they meet (Pain et al., 2006; Valentine, 1989). For Charlie, his familiarity with the place made the specific type of light all but superfluous to his experience, suggesting that his experience of changing light infrastructures is mediated by his embodied knowledge about and non-visual experience of his local neighbourhood (see also Cook \& Edensor, 2014; Degen \& Rose, 2012; Edensor \& Lorimer, 2015). 


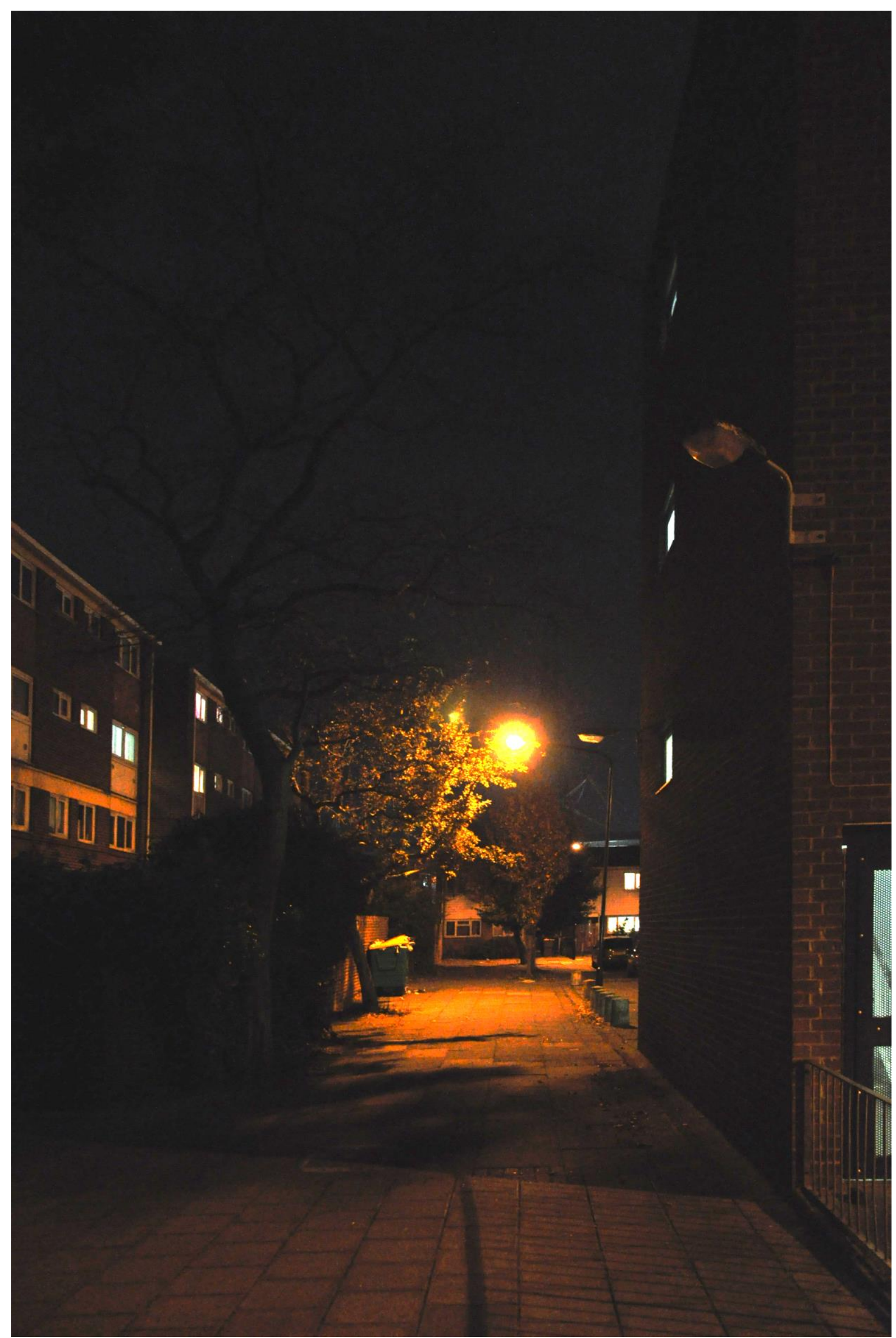

Figure 2: The view through the darkened alleyway. Source: Author's photograph. 
Eugene, 73, who also lives on his own in a ground floor flat in a council estate not far from Charlie in Custom House also noted how the lighting on his and adjacent estates, while sparse and dim, provided enough for him to see at night. His routine travel to the high street took him through the adjacent estates lit in patchy, dim SON lighting. Similar to Charlie, Eugene had no problems seeing despite the relative darker patches underneath trees, between lampposts, cars and down alleyways. As he argued, the pathways should not be "lit how you have a stadium or something...it gets light from the street anyway...[as long as] there is one [light], there is enough lights". Similar to the way Charlie talks about the density of light, visibility is a relative measure to Eugene that depends on the spatial distribution or dispersal of light, as it spills and bleeds from the street, providing visibility in darker patches (Jackle, 2001; see also Kumar, 2015; Valentine, 1989).

This became evident as we approached an alleyway where the light on the corner was out, but where we could still see towards our destination (see figure 2). Eugene commented: "even though there is not enough light here, then the place will be bright...you can see where you are going", "because, as I said, one can see through... I just mean to say that I see people". When Eugene approaches a dark space in motion, with attention focussed on where he is moving towards, the dark space dissolves because you "can see through" it. This notion of seeing through a darkened space (or as Charlie explained seeing where one is going even in half-light) suggests that when street lights 'fail', residents can still see because of the relative distribution of light and because it bleeds, raising two points. First, as argued by Valentine (1989) and by Pain et al. (2006) spaces that are characterised by low light levels can in fact yield positive responses from residents compared to brightly lit areas, because their experience depends on their familiarity with the space and on the presence of others. To Charlie and Eugene, dimly lit streets are not problematic because of their familiarity with them, but more importantly, because their embodied experience of walking through the streets recognises the importance of spillage. This leads to the second point, that stresses the importance of movement to how people experience light and darkness: moving through darkened spaces is less dependent on the actual light levels and more on the relative distribution of light across different spaces (Cook \& Edensor, 2014; Edensor \& Lorimer, 2015). Michel de Certeau has argued that "to travel is to see, but seeing is already travelling" (de Certeau quoted in Thrift, 1996, p. 296), suggesting the need to recognize that the visual experience of the lit city always unfolds in relation to the movement through it, and therefore the movement through light (see also, Sumartojo and Pink, 2017).

Recognising that both respondents are male, and therefore might feel more secure and less concerned about light in the public realm, their testimonies redirect attention from the quantitative measures of light towards the embodied experience of moving through and negotiating differently lit and darkened spaces. When negotiating changes in their lit environment, they no longer simply 'see' or 'see through' light and darkness, they make sense of its qualities by moving with them. While an upgrade of the lighting infrastructure might improve the quality of the light and the visuality of a space, it does not, as it is widely claimed, improve vision. Vision is shown to depend on habitual, embodied knowledge and on the relative distribution of light across differently lit and darkened spaces, revealing the role of lighting technologies in differentiating visibility and visuality.

\section{Seeing light}

The introduction of LEDs made many residents aware of the difference lighting can make to how spaces look and feel. Lifetime friends Lucie, 69 , and Jackie, 67 , took me on a walk to 
demonstrate this difference around their residential neighbourhood in Canning Town where all their pathways and alleyways were bathed in SON lights. Living close to her cousin, daughter, and grandchildren, Lucie would often walk the pathways in evenings which were lit in the "orange horrible stuff", that "seems to create this shadowy effect" and "dark patches". As we re-enacted a routine walk, they took me to an alleyway at the end of the turning with "no lighting", and despite "a lot of people" using it, deterred them from doing so. As we passed by the turning and stood in the light and looked at the space, Jackie remarked: "it doesn't look as bad as I thought it would be". Lucie agreed that "this is all right...this is quite bright down here, I didn't think it was like this". When standing in, and seeing through the light, it appeared brighter than when standing afar looking at the light. The discrepancy between how people anticipate they might feel about the lighting in their area - shaped by how the lighting makes the space look - and how the lighting actually is when they see through the light, reveals the role that the visual appearance plays in shaping preconceived understandings of our sensory world that are seemingly out of touch with our non-visual apprehension of it. Pain et al. (2006) similarly show that when residents express dissatisfaction with street lighting, this is often due to its colour or the micro-geographical features of sites rather than the actual light levels. To contrast the badly lit alley with a well-lit space, Lucie and Jackie took me to a pedestrian crossing outside Star Lane School, which recently had been refurbished with LEDs. Jackie noted that the LED was much better than the surrounding SON lights:

It is a blue lighting, it is not that orange one ... you've got a clearer view. When you come here ... stand here, and see how clear that looks ... and then now look over at the orange lighting. That's the difference of the colour in the lighting.

In comparison to the "eerie, dull, creepy feeling" elicited in SON light, the new "blue light" appeared "a lot brighter" to them because, as they argued, it "reflects better" and "just gives that ... clearer view", which ultimately makes "you feel confident walking here....you can see your face quite clear." In this instance, the LED lights improve how Lucie and Jackie see and how they feel about the lighting in their streets: the LEDs make the space look different which influences their preconceived ideas of how it will make them see. However, their judgement of what constitutes 'bad' or 'good' lighting rests more on visual appearance and aesthetic judgement made from a distance, rather than its sensory experience or non-visual apprehension when walking and seeing through it. While their experiences are clearly shaped by a change in lighting technology they realise that it is not seeing through the light that is problematic to them, but a range of other factors such as the way the space looks, its spatial layout, the presence of lack of people and so on. If we are to follow Foucault and Deleuze, this realisation that the SON light is actually not that bad suggests that rather than the specific technology posing a problem, it is the way it is configured into a wider apparatus or system that shapes how residents feel about certain technologies. Lucie and Jackie do not experience in a one-to-one relationship with a specific lighting technology, but through a relational web that encompasses local context, micro-geographical features, different light technologies, public imaginaries, memories, embodied knowledge, discourses and so on. 


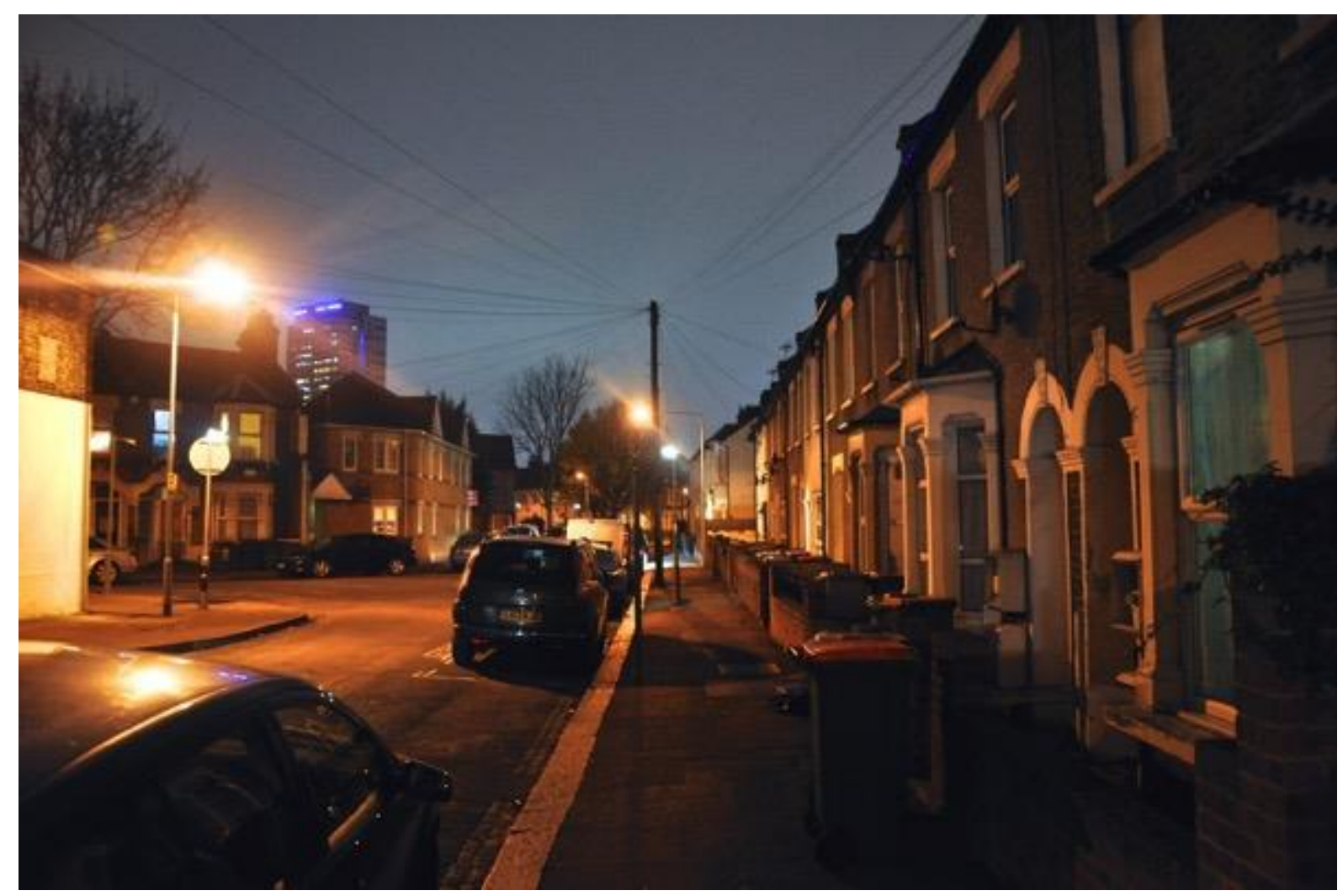

Figure 3: Approaching Lesley and Jan's home. Source: Author's photograph.

The significance of this wider infrastructural arrangement of lighting technologies was further exemplified by Lesley, 72, and Jan, 77, who took me on their weekly trip from their local bingo club in Canning Town, along Barking Road to their home in Plaistow - a terraced house, built in the early 20th century. They preferred to make the trip by car, especially in the winter months, parking on the parking lot across from the Centre, just off Barking Road (this has since been redeveloped into flats). The first approximately 500 metres of Barking Road have been refitted with $\mathrm{MH}$ lights as part of the regeneration of the central part of Canning Town, appearing a lot brighter and 'whiter' than the SON lights in the car park, further down Barking Road, and in the residential area where they live. They remarked how the lighting in these areas was "very, very poor", and anecdotally referred to how when returning after an evening of bingo to retain their car "you just got to remember where you put it", because they wouldn't be able to see it.

With the "good" lighting restricted to regenerated areas, the differently lit spaces they routinely move through became markers that shape how they relate differently to places. As Jan commented "it seems like, they only think of one end of it, yeah, and forget the rest of it", suggesting that they felt omitted from the upgrade and left with "very, very poor" lighting. However, as we arrived in their street, as seen on figure 3, and walked towards their front door, they confided in similar fashion to Lucie and Jackie that "we never had any problems coming home it isn't too bad". While the upgrade in lighting holds less importance for the visibility in each setting, it changes the visuality of space with profound implications for people's sense of belonging to the area and to the wider unevenly distributed development of the borough. Or to rephrase: vision is never constituted in a singular relation to the visuality of a city, but rather, as argued by Thompson, vision "is always shaped by a 
broader set of cultural assumptions and frameworks and by ... [that which] commonly accompany the visual" (2008, p. 57). In this case, the broader assumptions that accompany the visual change of the neighbourhood, by way of lighting, concern the cultural understandings of urban change, regeneration and how lighting somehow makes these uneven geographical development trajectories visible at night.

Such unevenness is not only visible in the colour difference, but in the day-today maintenance and upkeep as well. Similar to the incidents where lights were out along Charlie and Eugene's walks, the lighting in Jan and Lesley's street often goes out or gets smashed, with long waiting time for repairs making them rely on other, more contingent light sources:

when they turn that light off, which they do some times, then it is quite dark. I mean it could really do with a few more, couldn't it, because you have the lights in the houses, and once they are not on, obviously it is a lot darker isn't it

Their visual experience is compromised by a combination of forces, such as light quality, an interruption in its performance and insufficient maintenance.

The uneven distribution of technologies along the public infrastructure reveals a lack of what Ash Amin and Thrift call "fair access to infrastructure", which problematizes the access and recognition of people as part of "the commons we have built ourselves but continue to reserve for just a few human and nonhuman elites." (2017, p. 6) As Amin (2008, p. 22) further argues, "[w] hen the basics of shelter, sanitation, sustenance, water, communication and the like are missing, the experience of the city, of the commons and of others, is severely compromised". For Jan and Lesley, the problem is not that they cannot see or that the light is bad where they live, but the fact that they are made aware of not being included in the part of the common public, worthy of upgrade. Amin is highly critical of the role of authorities and officials in sustaining such uneven development of cities and calls for authorities to develop more progressive "politics of urban maintenance" in order to "make explicit the link between the techno-structure and the formation of a public." (Amin, 2008, p. 22) This point equally suggest that any lack of maintenance and upgrade can create social divisions that deteriorate the foundations for a public to emerge, and that the changing visuality that follows from upgrade of the lighting infrastructure can exacerbate social difference and inequality.

As Thompson contends classic understanding of the pubic sphere and public space rest on a premise of visuality: that people are "capable of being seen and heard by others" (2011, p. 63), suggesting that those who are not heard or not rendered visible are excluded from the public. In other words the upgrade and upkeep of lighting infrastructures should aim at providing visibility for people as well as of people, areas and neighbourhoods. Alongside Amin's 'politics of maintenance', it thus seems suiting to suggest the need for developing a 'politics of visibility,' one that recognises the role of lighting technologies in shifting the grounds of the visual and visible. Such a politics of visibility has much in common with Rancière's notion of politics, which Guy Baeten suggests "makes visible what was not to be seen, it turns into discourse what was previously qualified as noise" (Baeten, 2009, p. 245). By recognising the political importance of visibility in the upgrade and maintenance of lighting infrastructures, the hope is to emphasise the role that lighting technologies play in providing visibility in and of the public, rather than reducing particular people to mere noise. 
The point, however, is not that SON lights are bad and that all neighbourhoods should be upgraded with LED and $\mathrm{MH}$. Rather, I want to problematize the premise for initiating a luminous upgrade in the first place, and the effects of inadequate maintenance on the formation of a public.

\section{Living light}

As Jan and Lesley mentioned in the previous section, the light streaming from the neighbouring homes provide enough light for them to see when their street lights fail. Recognising the role of domestic light sources in shaping a public night, draws attention towards this slippage between private and public culture, this spillage from a host of unsolicited and contingent light sources such as homes, shops and vehicles into the public realm and its complementary role to the automated lighting infrastructure of the city.

Susie, 75, lives with her husband in a street of Victorian terraced houses, entirely lit in SON light. She noted the importance of domestic lighting in the street as it adds luminosity to and improves visibility while its symbolical presence gives her a sense of safety. As we were walking down the road she commented that "there are two houses there, and they have both got their lights on there, so that helps the road". The additional light sources increased the light levels in darker patches and was argued to deter potential criminal offenders, ensuring that "there would be less robberies". The importance of seeing people's homes illuminated in the street, indicating the presence of someone in the public realm, was emphasised by several interviewees as a crucial factor of the urban night that can compensate for the absence of police or natural surveillance. It is not important for residents to see into the home, to see people, or even to know them. Rather, seeing buildings and houses lit up by strangers as spaces of domestic use - as homes - were important for residents to feel confident and comfortable walking through the streets at night.

Recognising the importance of such 'domestic qualities' to the formation of a public, shares affinities with the extended notion of 'home' that Alison Blunt and Robyn Dowling argue is characterised by "processes of establishing connections with others and creating a sense of order and belonging as part of rather than separate from society" (2006, p. 14 emphasis added; see also Blunt \& Sheringham, 2018). Feelings that are often associated with home, such as a sense of belonging, comfort and safety (recognising that the domestic also is a site of fear, anxiety, violence and insecurity), therefore hinge on the relation people forge with others, and in the cases above the presence of domestic lights in the public realm prove crucial to developing a sense of home, or the lack hereof, in the city at night. The vernacular infrastructures of domestic and more intimate lighting is crucial to the ways people come to live together and come to form a public at night that is predicated on feeling confident and comfortable walking alone at night.

Recognizing a wider range of light sources, including commercial lights and traffic lights, Mary, 70, and Richard, 68, took me for a walk with their dog around their local neighbourhood in Plaistow. Walking down their street of terraced Victorian houses Mary noted: "see that's well-lit at the end where the shop lights are on, they have the signs". As we approached the street with the shops and lights she explained: "when you can see lights around you, like here, where you have shop lights and light coming from people's homes and lights from the traffic, you don't feel alone... [it] makes you not feel alone in the city". Due to 
the light streaming from a host of contingent and non-automated light sources solitude is not experienced as loneliness, and the residents do not feel vulnerable in the darkened night, which interestingly marks out a difference to rural areas, where Cook and Edensor (2014) suggest that when moving through inhabited areas, domestic lighting entices a sense of being alone. In the city, however, the potential presence of people, mediated through the interior luminosity from homes, shops or moving vehicles, "signals life" and makes it feel like "it's alive", allowing people to be alone in the city while feeling surrounded by the (absent) presence of others, feeling part of a common public at night. By characterising the vernacular lighting infrastructure as signals of life suggests the importance of 'living lights' in establishing a sense of living together in the city at night.

These examples further redirect attention away from quantitative measures of light towards how light connects people: living lights connect strangers in the night, and therefore hold tremendous potential for the formation of a public that recognises difference. This point shares affinities with Mikkel Bille's (2019) notion of 'atmospheric community' that with reference to Benedict Anderson's notion of 'imagined community' is practiced through the routines of lighting up people's homes (often with candle lights placed in the window sills) and letting the light stream out into the surrounds by leaving curtains open. In turn this enables people to see into other peoples' homes, and Bille argues that this culture is "established by normalized and skilled ways of seeing the world at the margins of attention, such as sensing the sound, movement or light of the atmospheric neighbor" (2019, p. 100). Similar findings of a local 'culture of openness' expressed through the use of windows and curtains are found in Norway (Garvey, 2005), Holland (van der Horst \& Messing, 2006), Bihar in rural India (Kumar, 2015). Through their study of Christmas light displays in Sheffield and Manchester, UK, Edensor and Millington similarly show how domestic light intentionally contributes to creating a "period in which generosity, family harmony and pleasure coexist" (Edensor \& Millington, 2009, p. 117).

Yet, my interviewees in east London intentionally avoided any such communication with the outside and instead drew curtains or installed lace curtains to prevent people from looking in, to create a more enclosed sense of interior space, or to refract light streaming in. The unintentional light spill that they contribute to and that they encounter when walking through the streets at night, streaming from peoples' homes onto the street should therefore be seen as a quite different to the culture of 'openness' (Bille, 2019; Garvey, 2005; van der Horst \& Messing, 2006), 'generosity' (Edensor \& Millington, 2010), and 'pride' or 'hospitality' (Kumar, 2015). Yet, the unintentional excess lighting streaming from shops, vehicles and people's homes should be recognised for its effect on people and the crucial role it plays in shaping a sense of comfort and confidence at walking alone at night. By recognising the softer infrastructure of vernacular and domestic lighting alongside the automated infrastructures of street lighting - whether upgraded or not, maintained or not - this section challenges the strictly visual aesthetic focus that underpins the widescale introduction of LED as a technological fix (LEDs will "make Newham look better", see London Borough of Newham, 2016a). Light spillage, contingent light sources and light clutter symbolises and affords a form of communal domesticity of the night time that is crucial to how people see, feel and do things in the urban public night. 


\section{Conclusion}

This article has shown how the changing contours of London's luminous landscape reveal broader shifts in its political and social geography. Joining a global trend of cities that promote the transition from electric to electronic lighting as panacea for combatting $21^{\text {st }}$ century evils such as urban crime, environmental degradation and austerity, London's upgrade to LED lighting is claimed to make the city look better, make its citizens feel safer, and develop smarter ways of living together, all, while consuming less energy. Responding to such claims this article critically assesses the techno-fixation of urban planners and policy makers in their quest to improve vision, visibility and the experience of the city, and shows how these registers relate to things different to lighting, by drawing attention towards the ways that people make sense of the shift 'from sodium to diodes'. In doing so, the article makes two contributions; one conceptual and one practical.

First, I follow in the steps of geographers (Edensor, 2017a; Shaw, 2018) and anthropologists (Bille, 2019; Pink \& Sumartojo, 2017) who have called for a change of frame in how scholars conceptualise cities from the perspective of the night and through lighting. Challenging the conventional understanding of light as a quantifiable measure that can be moulded to create and produce certain predefined activities and experiential effects, I foreground an embodied understanding of light that emerges through complex and often contradictory ways that people respond to, adapt and reframe light to fit into the parameters of everyday life. Rather than providing a self-referential system of cause and effect, a readymade background like a stage for urban processes to unfold, I show how people co-produce the urban lit environment as they make sense of changes to their sensorium when the light infrastructure fails, when it isn't sufficiently maintained or when it is, or is not, upgraded. In these instances people negotiate changes in the relative distribution of light and darkness, the changing visuality of differently lit spaces, and the vernacular infrastructure of the urban contingent, suggesting the need to conceptualise the nocturnal city as generative, emerging through a process of co-production. By recognising this contingent coproduction of the urban lit environment, I suggest that we might develop more inclusive grounds for developing a public, collective culture of the night time city, predicated on recognition (Amin, 2008; Thompson, 2011), equal access (Amin \& Thrift, 2017) and generosity (Edensor \& Millington, 2009, 2010).

Second, by investigating the uneven geographical distribution of and access to different forms of light and darkness, I have called for the need to develop a politics of visibility (cf. Thompson, 2011) that challenges the underlying assumptions of policy makers and planners who foreground an almost endless promise of benevolent changes brought about by a transition to LED. Instead, I show that the contingency of luminous circumstances provide an aesthetics of communal domesticity that both provides visibility and helps foster a sense of safety and belonging in ways that challenge conventional assumptions. This is evident in the examples that show how darkened spaces are made visible through bleeding SON light, suggesting that visibility can be achieved at low light levels if its relative distribution is considered. And furthermore, that the type of bleed that occurs as light spills from the private realm of the home, the shop or a car into the public domain and wider city, adds an indispensable and affirmative domestic atmosphere to the nocturnal city, which makes people see better, feel safer and more confident walking alone without feeling lonely. 
This last point is clearly at odds with critics who bemoan the loss of the night and darkness at the expense of light pollution with detrimental effects on human and biological life in cities (Bogard, 2013; Crary, 2013; Gandy, 2017; Meier et al., 2015). Yet, I want to stress that recognising the importance of light bleed is a crucial step in ensuring the development of lighting infrastructures that curtail the impacts on biological life, while savouring the social importance of 'seeing light'. As I have argued elsewhere (see Ebbensgaard, forthcoming) the skill and sensitivity of lighting designers promise ways of lighting spaces in ways that are conducive to more socially and environmentally just forms of nocturnal life (see also Edensor, 2017a), and I want to claim that geographers and social scientists should, and could, do more to bring this knowledge into dialogue with decision makers, ensuring that decisions on upgrading and maintaining the vital infrastructures of the future cities, are taken on informed grounds.

\section{Bibliography}

Amin, A. (2008). Collective culture and urban public space. City, 12(1), 5-24. https://doi.org/10.1080/13604810801933495

Amin, A., \& Thrift, N. (2017). Seeing like a city. Cambridge: Polity Press.

Baeten, G. (2009). Regenerating the Southbank: reworking community and the emergence of post-political regeneration. In R. Imrie, L. Lees, \& M. Raco (Eds.), Regenerating London: Governance, Sustainability and Community in a Global City (pp. 237-253). Abingdon and New York: Routledge.

Beaumont, M. (2015). Night Walking: A Nocturnal History of London. London: Verso Books.

Bille, M. (2014). Lighting up cosy atmospheres in Denmark. Emotion, Space and Society, 1-8. https://doi.org/10.1016/j.emospa.2013.12.008

Bille, M. (2019). Homely Atmospheres and Lighting Technologies in Denmark: Living with Light. London: Bloomsbury.

Blunt, A., \& Dowling, R. (2006). Home. London and New York: Routledge.

Blunt, A., \& Sheringham, O. (2018). Home-city geographies: Urban dwelling and mobility. Progress in Human Geography. https://doi.org/10.1177/0309132518786590

Bogard, P. (2013). The End of Night: Searching for Natural Darkness ins an Age of Artificial Light. London: Harper Collins Publishers.

Cook, M., \& Edensor, T. (2014). Cycling through Dark Space: Apprehending Landscape Otherwise. Mobilities, 0101(December), 1-19. https://doi.org/10.1080/17450101.2014.956417

Crary, J. (2013). 24/7. Verso Books. 
Degen, M., DeSilvey, C., \& Rose, G. (2008). Experiencing visualities in designed urban environments: Learning from Milton Keynes. Environment and Planning A, 40, 19011921.

Degen, M., \& Rose, G. (2012). The Sensory Experiencing of Urban Design: The Role of Walking and Perceptual Memory. Urban Studies, 49(15), 3271-3287.

Degen, M., Rose, G., \& Basdas, B. (2010). Bodies and everyday practices in designed urban environments. Science, 23(2), 60-76.

Deleuze, G. (1992). What is a Dispositif? (T. J. Armstrong, Ed.), Michel Foucault: Philosopher. New York: Routledge.

Ebbensgaard, C. L. (forthcoming). Standardised difference: challenging uniform lighting through standards and regulation. Urban Studies

Edensor, T. (2017a). From Light to Dark: Daylight, illumination and Gloom. Minneapolis and London: University of Minnesota Press.

Edensor, T. (2017b). Seeing with light and landscape: a walk around Stanton Moor. Landscape Research, 42(6), 616-633. https://doi.org/10.1080/01426397.2017.1316368

Edensor, T., \& Lorimer, H. (2015). "Landscapism" at the speed of light: Darkness and illumination in motion. Geografiska Annaler, Series B: Human Geography, 97(1), 1-16. https://doi.org/10.1111/geob.12062

Edensor, T., \& Millington, S. (2009). Illuminations, class identities and the contested landscapes of Christmas. Sociology, 43(1), 103-121.

Edensor, T., \& Millington, S. (2010). Christmas light displays and the creative production of spaces of generosity. In T. Edensor, D. Leslie, S. Millington, \& N. M. Rantisi (Eds.), Spaces of vernacular creativity: Rethinking the cultural economy (pp. 170-182). Abingdon, Oxon: Routledge.

Ekirch, A. R. (2005). At Day's Close: A History of Nighttime. London: Phoenix.

Falchi, F., Cinzano, P., Duriscoe, D., Kyba, C. C. M., Elvidge, C. D., Baugh, K., ... Furgoni, R. (2016). Supplement to: The New World Atlas of Artificial Night Sky Brightness. GFZ Data Services., (June), 1-26.

Falchi, F., Cinzano, P., Elvidge, C. D., Keith, D. M., \& Haim, A. (2011). Limiting the impact of light pollution on human health, environment and stellar visibility. Journal of Environmental Management, 92(10), 2714-2722. https://doi.org/10.1016/j.jenvman.2011.06.029

Foucault, M. (1977). Discipline and Punish: The Birth of the Prison. New York: A Division of Random House. 
Gandy, M. (2017). Negative Luminescence. Annals of the American Association of Geographers, 107(5), 1090-1107. https://doi.org/10.1080/24694452.2017.1308767

Garvey, P. (2005). Domestic Boundaries: Privacy, Visibility and the Norwegian Window. Journal of Material Culture, 10(2), 157-176. https://doi.org/10.1177/1359183505053073

Graham, S., \& Marvin, S. (2001). Splintering Urbanism: Networked Infrastructures, technological mobilities and the urban condition. London and New York: Routledge.

Greater London Authority. (2015). The Propensity for Social Exclusion of Older People in London, (December), 25. Retrieved from https://files.datapress.com/london/dataset/propensity-for-social-exclusion-of-olderpeople-in-london--report-/2016-01-06T12:47:22/CIS2015-06 Propensity for Social Exclusion of Older People in London.pdf

IES. (2017). PS-09-17: IES Board Position on AMA CSAPH Report 2-A-16, Human and Environmental Effects of Light Emitting Diode (LED) Community Lighting. Retrieved June 5, 2018, from https://www.ies.org/policy/position-statements/ies-board-position-onama-csaph-report-2-a-16-human-and-environmental-effects-of-light-emitting-diode-ledcommunity-lighting/

Jackle, J. A. (2001). City Lights: Illuminating the American Night. Baltimore, MD: The John Hopkins University Press.

Koch, R., \& Latham, A. (2012). Rethinking urban public space: Accounts from a junction in West London. Transactions of the Institute of British Geographers, 37(4), 515-529. https://doi.org/10.1111/j.1475-5661.2011.00489.x

Koslofsky, C. (2011). Evening's Empire: A History of the Night in Early Modern Europe. Cambridge: Cambridge University Press.

Krause, K. (2015). Regulating Urban Lighting: Prospects for Institutional Change. In J. Meier, U. Hasenöhrl, K. Krause, \& M. Pottharst (Eds.), Urban Lighting, Light Pollution and Society (pp. 125-140). New York and London: Routledge.

Kumar, A. (2015). Cultures of lights. Geoforum, 65, 59-68. https://doi.org/10.1016/j.geoforum.2015.07.012

Latham, A., \& Wood, P. R. H. (2015). Inhabiting infrastructure: Exploring the interactional spaces of urban cycling. Environment and Planning A, 47(2), 300-319. https://doi.org/10.1068/a140049p

London Borough of Newham. (2013). Understanding Newham 2013: Newham Household Panel Survey Wave 7 Survey Findings.

London Borough of Newham. (2016a). Mayor's promise 7. Retrieved October 16, 2016, from https://www.newham.gov.uk/Pages/Services/mayors-priorities.aspx 
London Borough of Newham. (2016b). Understanding Newham 2015: Findings from Wave 8 of the Newham Household Panel Surveys. London.

London Borough of Newham. (2018). Newham switches on to street lights campaign. Retrieved May 24, 2018, from https://www.newham.gov.uk/Pages/News/Newhamswitches-on-to-street-lights-campaign.aspx

Mattern, S. (2014). Library as Infrastructure,. Places Journal, June. Retrieved from https://placesjournal.org/article/library-as-infrastructure/\#0

McQuire, S. (2005). Immaterial architectures: Urban space and electric light. Space and Culture, 8(2), 126-140.

Meier, J., Hasenöhrl, U., Krause, K., \& Pottharst, M. (2015). Urban Lighting, Light Pollution and Society. (J. Meier, U. Hasenöhrl, K. Krause, \& M. Pottharst, Eds.). New York and London: Routledge.

Meier, J., \& Henckel, D. (2017). Illuminating urban Zones of extended activity: an exploration into temporal profiles of urban functions, public transport and artiflcial lighting. In G. Drevon, L. Gwiadzinski, \& O. Klein (Eds.), Chronotropics: Readings and Writings on a World in Movement (pp. 128-135). Grenoble: Elya Editions. Retrieved from https://halshs.archives-ouvertes.fr/halshs-01710577/document

Melbin, M. (1987). Night as Frontier: Colonizing the World After Dark. New York: The Free Press.

Middleton, J. (2010). Sense and the city: exploring the embodied geographies of urban walking. Social \& Cultural Geography, 11(6), 575-596. https://doi.org/10.1080/14649365.2010.497913

Middleton, J. (2011). "I'm on autopilot, I just follow the route": Exploring the habits, routines, and decision-making practices of everyday urban mobilities. Environment and Planning A, 43(12), 2857-2877. https://doi.org/10.1068/a43600

NASA. (2015). London at night.

Nye, D. E. (2013). When the lights went out: A history of blackouts in America. America: The MIT Press.

Pain, R., MacFarlane, R., Turner, K., \& Gill, S. (2006). "When, where, if, and but": Qualifying GIS and the effect of streetlighting on crime and fear. Environment and Planning $A$, 38(11), 2055-2074. https://doi.org/10.1068/a38391

Pink, S., \& Leder Mackley, K. (2014). Moving, Making and Atmosphere: Routines of Home as Sites for Mundane Improvisation. Mobilities, (September 2014), 1-17. https://doi.org/10.1080/17450101.2014.957066 
Pink, S., \& Sumartojo, S. (2017). The lit world: living with everyday urban automation. Social \& Cultural Geography, 9365(April), 1-20.

https://doi.org/10.1080/14649365.2017.1312698

Pløger, J. (2008). Foucault's Dispositif and the City. Planning Theory, 7(1), 51-70. https://doi.org/10.1177/1473095207085665

Rose, G., Degen, M., \& Basdas, B. (2010). More on "big things": building events and feelings. Transactions of the Institute of British Geogpraphers, 334-349.

Schivelbusch, W. (1995). Disenchanted Night: The Industrialization of Light in the Nineteenth Century. Berkeley and Los Angeles, CA: University of California Press.

Schlör, J. (1998). Nights in the Big City. London: Reaktion Books.

Schulte-Römer, N. (2013). Fair framings: arts and culture festivals as sites for technical innovation. Mind \& Society, 12(1), 151-165. https://doi.org/10.1007/s11299-013-01148

Schulte-Römer, N. (2015). Innovating in public - the introduction of LED lighting in Berlin and Lyon. Technischen Universität Berlin. Retrieved from https://depositonce.tuberlin.de/handle/11303/5211

Scott, J. (1998). Seeing Like A State: How Certain Schemes to Improve the Human Condition Have Failed. New Haven, CT: Yale University Press.

Secured by Design. (2016). Secured by Design: Homes 2016. London.

Shaw, R. (2014). Street-Lighting in England and Wales: New Technologies and Uncertainty in the Assemblage of Street-Lighting Infrastructure. Environment and Planning A, 46, 1-16. https://doi.org/10.1068/a130313p

Shaw, R. (2018). The Nocturnal City. London: Routledge.

Silver, J. (2015). Disrupted Infrastructures: An Urban Political Ecology of Interrupted Electricity in Accra. International Journal of Urban and Regional Research, 39(5), 9841003. https://doi.org/10.1111/1468-2427.12317

Simone, A. (2014). People as infrastructure: Intersecting fragments in johannesburg (2004). The People, Place, and Space Reader, 16(3), 241-246. https://doi.org/10.4324/9781315816852

Spinney, J. (2010). Performing resistance? Re-reading practices of urban cycling on London's South Bank. Environment and Planning A, 42(12), 2914-2937. https://doi.org/10.1068/a43149 
Sumartojo, S., \& Pink, S. (2017). Moving Through the Lit World: The Emergent Experience of Urban Paths. Space and Culture, 120633121774107.

https://doi.org/10.1177/1206331217741079

Sutton, paul C., \& Elvidge, C. D. (2015). Night Lights: An Indicator of the Good Life? In J. Meier, U. Hasenöhrl, K. Krause, \& M. Pottharst (Eds.), Urban Lighting, Light Pollution and Society (pp. 284-298). New York and London: Routledge.

Thompson, J. B. (2011). Shifting Boundaries of Public and Private Life. Theory, Culture \& Society, 28(4), 49-70. https://doi.org/10.1177/0263276411408446

Thrift, N. (1994). Inhuman Geographies: Landscapes of Speed, Light and Power. In P. Cloke, M. Doel, D. Matless, M. Philips, \& N. Thrift (Eds.), Writing the Rural: five cultural geographies (pp. 191-248). London: Paul Chapman Publishing.

Thrift, N. (1996). Spatial Formations. London: Sage.

Valentine, G. (1989). The geography of women's fear. Area, 21(4), 385-390.

Van der Horst, H., \& Messing, J. (2006). "It's Not Dutch to Close The Curtains": Visual Struggles on The Threshold Between Public \& Private in a Multi-Ethnic Dutch Neighborhood. Home Cultures, 3(1), 21-37. https://doi.org/10.2752/174063106778053264

Watson, S. (2015). Mundane objects in the city: Laundry practices and the making and remaking of public/private sociality and space in London and New York. Urban Studies, 52(5), 876-890. https://doi.org/10.1177/0042098014531630 